
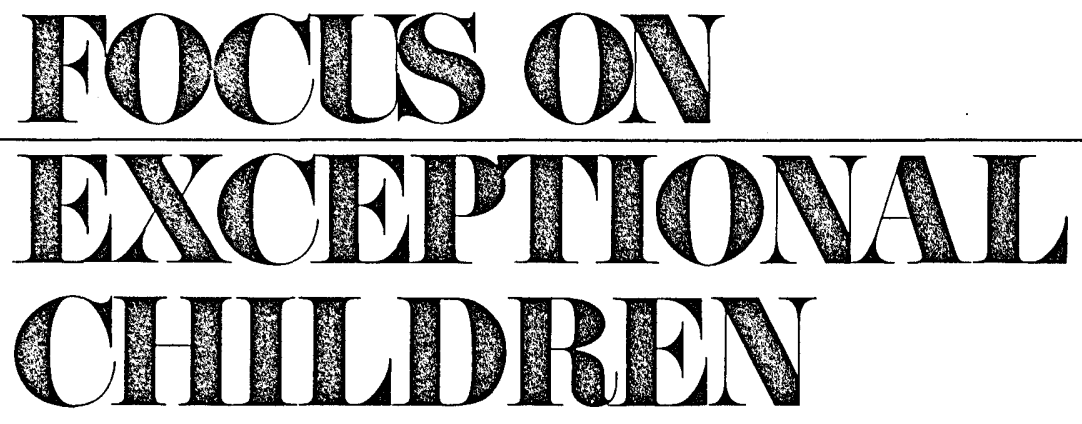

\title{
Selection and Initiation of a Nonvocal Communication Program for Severely Handicapped Students
}

\author{
Paul A. Alberto, Elizabeth Garrett, Thomas Briggs, and Forrest Umberger
}

As the public schools assume responsibility for the education of more severely and multiply handicapped students, special education teachers and speech pathologists increasingly encounter students for whom traditional verbal language programming is not appropriate. With these students the challenge is to develop functional communication through nontraditional communication systems. These systems are referred to as auxiliary (nonvocal) language programs; they include manual communication, communication aids, and communication codes (Nietupski \& Hamre-Nietupski, 1979).

The decision to initiate an auxiliary communication program cannot be made by a single teacher or clinician. Integrated consideration must be given to the language, cognitive, social, emotional, and physical characteristics of the student. It is a decision, therefore, requiring complex professional judgment based on input from members of a variety of disciplines (e.g., special education, speech pathology, physical therapy, occupational therapy, and psychology) and the student's parents.

\section{THE SEVEN-STEP DECISION-MAKING SEQUENCE}

We are proposing here a seven-step sequence for decision making to assist the interdisciplinary team in making a systematic and logical communication programming decision (see Figure 1). This decision sequence will guide the team from the initial consideration of a student's verbal potential, through the selection of an appropriate alternative nonvocal program, and finally to the procedure necessary for successful program initiation.

\section{Decision Step 1:}

\section{Should a Nonvocal System be Considered?}

The first decision to be made upon a student's referral for auxiliary communication training is whether a nonvocal system is appropriate for the student at this time.

The authors are all affiliated with Georgia State University, where Paul Alberto is Associate Professor and Program Director-Severely Handicapped, Elizabeth Garrett and Thomas Briggs are graduate students in Special Education, and Forrest Umberger is Associate Professor and Program Director-Speech Pathology. 
For some students trial speech therapy or cognitive instruction may be considered prior to, or in conjunction with, nonvocal programming. To assist in making this decision, six factors should be considered.

1. Evaluation of the vocal mechanism. When evaluating a student, consideration must be given to the structure of the vocal mechanism and the nature of the student's oral reflexes. Are there physiological impediments to successful vocal production? An abnormality of the vocal mechanism that prevents phonation or production of intelligible speech is an immediate indicator that a nonvocal system is necessary. Examples of mechanism abnormalities include paresis of the tongue that impairs the timing of the rapid ballistic movement, contractions or atrophy of the palate, and mandibular facet slip (Achilles, 1955).

Evaluative attention must also be given to the student's oral reflexes. Uncontrolled release of primitive reflexes may interfere with voluntary and selective control of the speech mechanism. Mysak (1963) has listed the following as indicators of these uncontrolled reflexes:

- Cephalic reactions: irregular movement of head upon stimulation of facial area.

- Facial response: pouting protrusion of lips upon tapping around lips.

- "Rooting" reactions: movement of face toward side of tactile stimulus of lips and mouth.

FOCUS ON EXCEPTIONAL CHILDREN (ISSN 0015-511X) (USPS 203-360) is published monthly except June, July, and August as a service to teachers, special educators, curriculum specialists, administrators, and those concerned with the special education of exceptional children. This journal is abstracted and indexed in Exceptional Child Education Resources, and is also available in microform from Xerox University Microfilms, Ann Arbor, Michigan. Subscription rates, $\$ 15.00$ per year. Copyright 1983, Love Publishing Company. All rights reserved. Reproduction in whole or part without written permission is prohibited. Printed in the United States of America. Second class postage is paid at Denver, Colorado. POSTMASTER: Send address changes to:

$$
\begin{gathered}
\text { Love Publishing Company } \\
\text { Executive and Editorial Office } \\
1777 \text { South Bellaire Street } \\
\text { Denver, Colorado } 80222 \\
\text { Telephone (303) } 757-2579
\end{gathered}
$$

\section{EDITORIAL BOARD}

Edward L. Meyen

University of Kansas

Richard J. Whelan

University of Kansas Medical Center Publisher
- Biting reflex: biting action upon placing stimulus object between teeth or gums.

- Suckling reflex: forward upward and backward movement of tongue upon touching stimulus to teeth, tongue, gums, or hard palate.

- Chewing reflex: chewing movements resulting from placing stimulation object between teeth.

2. Quality of the student's current communication. Although a student may be vocalizing, the quality of communication may not be sufficiently functional in all current or future settings. If the intelligibility of a student's present communication abilities is limited to a select, familiar audience (e.g., teacher, parent), communication is not truly functional. When addressing the question of functional quality of communication, it should be required that the student's communication be understood by at least three people who are unfamiliar with the student, in at least three settings (Vanderheiden, 1981). This is especially important when considering a student's need to move between educational placements (e.g., special education class to regular education class) and to participate in vocational and community experiences outside the school setting.

When evaluating the quality of speech production of students exhibiting neuromuscular handicaps, it should be remembered that a majority of these children's speech is dysarthric. Specifically, the student's capacity to produce smooth, coordinated motor responses affecting potential intelligibility is inhibited by a group of motor disorders affecting articulation, respiration, and voice (Nicolosi, Harryman, \& Kresheck, 1978). Evaluation of these components of production may lead to an interim decision for speech therapy, prior to a final decision for a nonvocal program.

The articulation of neurologically impaired children reflects deficits in sounds that require fine coordination and ballistic movements of the tongue and other musculature. The speech sounds of a student with cerebral palsy, for example, may be distorted because of the slow rate and laborious movements of the speech musculature. Some sounds may be omitted because of the time element; paralysis or sounds that can be produced with less effort may be substituted. Irwin's (1961) articulation test for use with cerebral palsied children may provide useful information in deciding whether a student should be considered for a nonvocal system.

Observation of respiration during speech may reveal inadequate breathing caused by weak musculature, opposition of the muscles of inhalation and exhalation, or improper coupling of the breath stream to the nasal passages as a result of palatal paresis. If the student lacks 

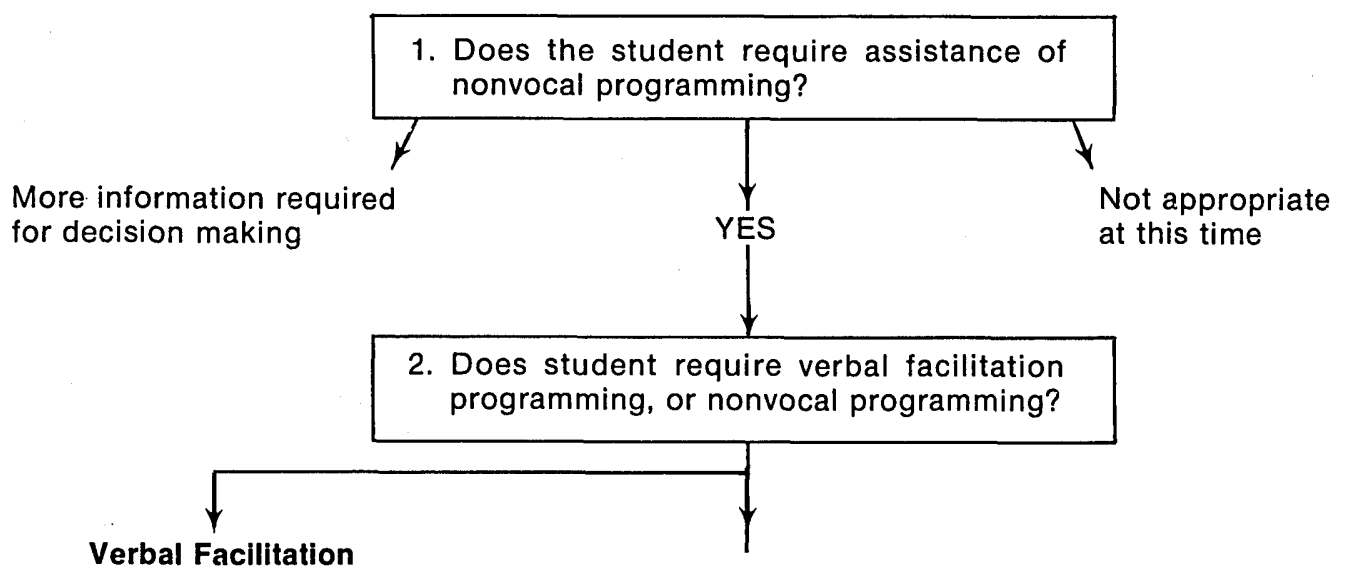

Programming

- Construction of verbal and manual language

- Fade use of manual

Nonvocal

Programming

3. Which category of nonvocal communication is appropriate?

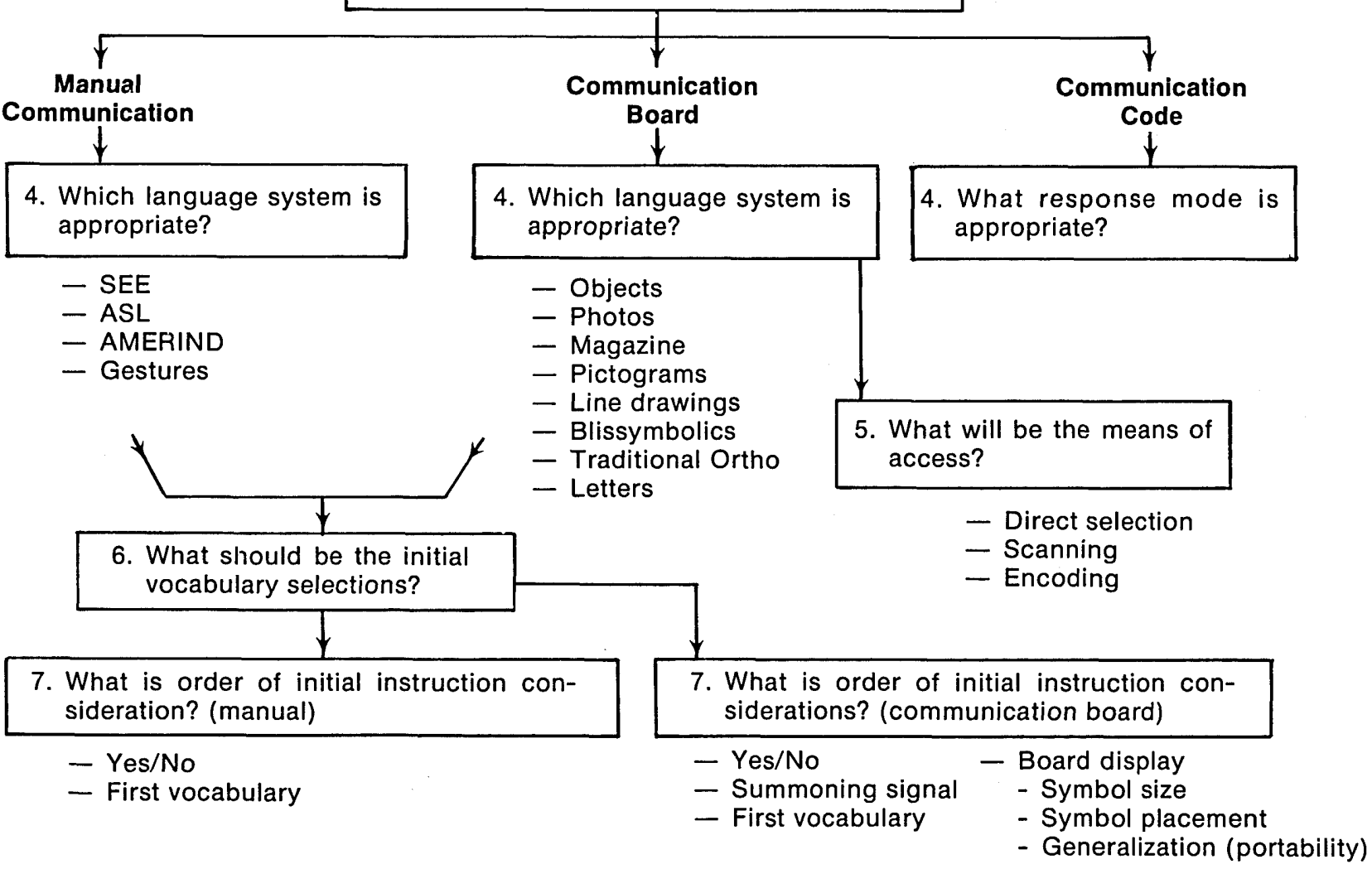

FIGURE 1 
control of breathing or breath-stream management because of release phenomena or inability to inhibit primitive reflexes, the physical therapist may be able to select reflex inhibiting postures that will allow the student to exert voluntary control over the breathing mechanism. The objective is for the student to eventually inhibit the interfering reflex phenomena in the absence of the reflex inhibiting postures.

According to Mecham, Berko, Berko, and Palmer (1966), voice difficulties require only the ability of the examiner to recognize normal voice patterns and quality. To assess adequacy of voice for communication purposes, they have suggested the following questions:

- Are intensity and intensity-change adequate to meet the needs of the average speaking situation?

- Is the pitch flexible and appropriate for the age and sex of the individual?

- Is the quality unusually nasal or hoarse, etc.?

- Can a steady tone be prolonged at least 10 seconds?

- Are variations in the voice pitch and intensity smooth and controlled or jerky and irregular?

- Do prosodic aspects of the voice sound normal, or does the student sound like he/she has a peculiar accent?

- Can the student coordinate voice with articulation (i.e., produce appropriate voice for voiced sounds and eliminate voice on voiceless sounds)?

- Does the voice sound metallic or raspy?

- Does voice pitch break into a falsetto occasionally?

The primary question to answer when evaluating voice production is not whether the voice quality is within "normal" limits as measured against the general population, but whether the voice quality deviates sufficiently to mask out intelligibility of speech articulation. A student who may sound strange as a result of a voice quality deviation, but who is still intelligible to naive listeners, would probably not be a candidate for a nonvocal communication system. For students exhibiting voice qualities that interfere with speech articulation intelligibility, a period of trial voice therapy would be the probable choice before making a decision regarding a nonvocal communication system.

3. Current cognitive functioning. The relationship of the emergence of an individual's intentional communication (i.e., gestures and holophrastic speech) with the attainment of Stage $V$ of the sensorimotor period (Piaget, 1952) continues to receive the attention of language researchers (Bates, 1976; Bates, Camaioni, \& Volterra, 1975; Ingram, 1981; Reichle \& Yoder, 1979). Chapman and Miller (1980) have suggested that mastery of Stage V is a prerequisite to successful use of an auxiliary communication system. With mastery of Stage V the student has developed a number of cognitive abilities. The abilities of attending, imitation, and an understanding of causality are of primary importance to the coordination of communication and are considered to be prerequisite to effective communication programming.

Attending is a basic cognitive function that involves the ability to focus upon an object in space visually, auditorially, or tactually, and track the object as it changes position. Attending is essential for the instruction of a nonvocal system. For example, in the case of a manual system, the student must be able to visually attend to the individual who performs a sign. In the case of a communication board system, the student must be able to attend to the symbols that appear on the board. Furthermore, nonvocal systems with deaf-blind students require attention to tactile stimuli.

Associated with the prerequisite ability to attend is the ability to perform successful imitation. Prior to auxiliary communication instruction, the student must be able to imitate motor responses. These may be either the motor responses necessary for imitation of a manual sign, or imitation of the movements used in selecting a symbol on a communication board.

Although attending and imitation are practiced during earlier sensorimotor levels, the higher order language prerequisite of recognition of causality does not come into place until mastery of Stage V (Piaget, 1952). Causality is the ability to understand the relationship between cause and effect. With mastery of Stage V, the student not only understands that his/her behavior will have a consequence that alters the environment, but also realizes that tools may be used as part of his/her behavior to produce a desired effect. For example, the child pulls a small rug to retrieve an out-of-reach object resting on the rug (Flavell, 1977); the child understands that a spoon can be used to get pudding from a bowl to his/her mouth. Similarly, gestures and holophrastic speech must be understood by the child as tools (the means) to produce a desired effect (e.g., pointing to or saying "cookie" prompts another person to give the child a cookie). This recognition of the use of language as a tool for change is essential to intentional communication.

Complex or expanded language ability (i. e., beyond the one-word stage) is associated with mastery of Stage VI of the sensorimotor period (Bates et al., 1975; Ingram, 1981). Stage VI is the culmination of the student's ability to "reproduce an absent model through memory" (Robinson \& Robinson, 1978). This ability is characterized as an understanding of object permanence. 
Object permanence is demonstrated by a student's understanding that when a stimulus disappears from the visual, auditory, or tactual field, it still has existence. Language becomes the symbolic representation of absent objects or concepts. The understanding that a concept exists in the absence of an immediate referent enables the student to use language representationally to effect environmental change. With the understanding of object permanence, the student's verbalizations and gestures are no longer stimulus-bound.

Coincident with mastery of sensorimotor Stage VI, breadth of vocabulary and length of utterance increase (Ingram, 1981). Therefore, to consider whether a communication system should involve expanded vocabulary and multi-word utterances, the degree of a student's understanding of object permanence should be considered.

4. Previous verbal training attempts, student age, and remaining instructional time. Before initiating nonvocal training, one must evaluate the data resulting from prior instructional attempts at verbal language training. The teacher and the speech pathologist must make a determination that, after good faith efforts at verbal language instruction over time, the student has not made expected progress (Scheuerman, Baumgart, Spisma, \& Brown, 1976). Within the analysis, the teacher and clinician must decide if they also have been able to deal effectively with interfering behaviors, such as stereotypic behaviors, to validate that these have not been the cause of delayed language acquisition. Elimination of interfering behavior should be addressed prior to a change in language training approaches.

It is also necessary to determine whether lack of progress or attempts at communication may be attributed to inhibition for emotional rather than cognitive/ language or production reasons. If so, intervention to meet the social/emotional needs of the student may be necessary before beginning a nonvocal program.

Consideration of chronological age in relationship to developmental age or cognitive level is necessary. A reasonable delay in acquisition of verbal language should be expected as a function of the student's diminished level of cognitive functioning. The student may reach a chronological age or grade level at which the expectation of verbal competence is not reasonable given that the time remaining in the educational setting is so limited. At this point, the immediate need for functional communication takes precedence over continued emphasis on verbal language training and requires initiation of an alternative communication program.

5. Analysis of current expressive and receptive language levels. If a significant discrepancy between expres- sive and receptive vocabulary exists, a nonvocal system should be considered. That a student understands a larger vocaulary than he/she uses is not unexpected. But a comparative assessment of receptive and expressive vocabulary that reveals a significant expressive lag may indicate the presence of production obstacles, particularly when the lag is as much as two years. A nonvocal system can circumvent product impediment. Thus, for students with significant expressive/receptive discrepancy, a nonvocal system should be considered as a means toward recognizing language potential indicated by the higher receptive measure.

6. Recognition of the student's current attempts at communication. Prerequisite to initiation of a nonvocal program is the student's recurrent attempts to communicate (Vanderheiden, 1981). These attempts may be recognized by the presence of metacommunication, functionalmotor communication, or differentiated vocalizations.

Metacommunication is evidenced when the student responds in recognizable, consistent patterns to changes in his/her environment. These responses may be vocalizations such as crying when in discomfort and laughing when being tickled. Metacommunication indicates expressive communication at the most elementary level.

Functional-motor communication is evidenced when the student uses motor behavior to indicate wants or needs. This may be represented by students' pointing to desired objects or pulling the teacher in their direction.

Differentiated vocalizations are consistent pairings of nonstandard phonations with objects and experiences. Because of their pattern of association, they become recognizable as expressive cues for environmental referents.

\section{Decision Step 2: \\ Should a Verbal Facilitation Program be Initiated?}

An augmentation program of nonvocal techniques is a temporary support system. Its purpose is to facilitate verbal communication for a student with an intact vocal mechanism. The primary instructional goal, therefore, remains that of verbal competence.

Selection of a facilitation approach rather than a full nonvocal approach may be considered if current verbal language usage is limited as a result of (a) poor articulation or other intelligibility problem, (b) minimal vocabulary pool, (c) discrepancy between receptive and expressive capability, (d) minimal degree of language generalization, and (e) inhibition because of emotional problems.

Manual signing is a frequently used facilitation approach. Current data suggest that use of a signing system 
will not inhibit development of verbal language (HarrisVanderheiden, Brown, MacKenzie, Reiner, \& Scheibel, 1975). In fact, recent studies have reported that signing may enhance development of verbal language (Grinnell, Detamore, \& Lippke, 1976; Kahn, 1975; Kotkin \& Simpson, 1976; Reich, 1978). Speculation on the facilitative role of manual communication involves several theories. Initiation of a sign may serve as a supplementary discriminative stimulus for making an oral response. The sign may give the student a constant feedback loop for verbal expression, or formation of the sign may provide a pacing monitor as a guide for production of verbal language as the sign user pairs verbalization with the sign. Production of the sign may serve to distract the student from anxiety he/she has developed or associated with production of the verbalization.

Because manual systems have been demonstrated to facilitate the emergence of language, manual communication is the nonvocal program of choice to enhance a student's skills in verbal expression. As verbal responses increase, manual augmentation is progressively faded (Schaeffer, 1980; Schaeffer, Kollinzas, Musil, \& McDowell, 1977).

\section{Decision Step 3: \\ Which Nonvocal Category Should be Selected?}

After deciding that the student is indeed a candidate for nonvocal communication training, the next determination is which of the three categories of nonvocal communication - manual communication, communication board, or communication code - would best suit the needs and capabilities of this particular student. To make this decision, the following information should be gathered and considered.

1. Does the student currently gesture? When the student is making attempts at communication, is this gesturing to indicate some item that he/she wants or some feeling about himself/herself? Indications that the student does consistently use gestures in this way support a decision for a manual system.

2. What is the student's degree of visual acuity? A student with poorer visual acuity is more likely to be a candidate for a communication board system. A teacher cannot alter the size of the signing hand to accommodate visual impairment, but one can easily alter the size of symbols placed on a communication board or raise symbols using clay or wooden cutouts similar to a Braille concept.

3. What is the efficiency of the student's imitation skill? The more efficient the student is at imitating, the more one would lean toward a manual system. Because of the complex patterns of movement involved in producing a sign, the student's imitation ability must be efficient and consistent to ensure accuracy and intelligibility. Alternatively, if the student is less efficient at imitating, one would lean toward a communication board. The only imitation required if the student is going to be a board user is the ability to imitate the singlesymbol selection response the teacher models.

4. What is the student's fine-motor capability and range of motion? The more proficient the student is in fine-motor skills, the more likely a candidate he/she is for a manual system, as he/she will be able to make the intricate fine-motor movements necessary for forming signs. In the case of the motorically limited student, a board system requires a single operant response by the student to select the appropriate symbol. In most instances this response will be a pointing response or a movement to depress a switch. Technological aids can enhance a simple response (e.g., head movement, puff of air, slight finger movement) and couple that response with an electronic board system. While a signing system may require expansive use of the upper extremities, and therefore a wide range of motion, a board system may incorporate technology and prosthetic devices to facilitate symbol selection.

5. What is the degree of the student's memory deficit? The greater the memory deficit, the more is the indication for a board system. When the student uses a communication board, the symbols are static and in constant view. A board system presents ready recognition memory cues. A signing system requires the student to maintain all the signs and all their referents in memory without concrete retrieval or recall memory cues. Thus, a board system best assists students who have dificulty with memory and retrieval skills.

6. What is the degree of necessity, current or potential, for naive communicators to have access to the student's communication system? The more diverse the group of individuals with whom the student comes in contact, the greater is the need for a nonvocal system that can be immediately engaged and understood. The need for access to a large, diverse community supports implementation of a communication board system. Regardless of symbol choice on a board, the printed word always appears in conjunction with the symbol. Conversely, a manual system is efficient only with another person who is equally fluent in that particular sign system.

7. To what degree will the student be able to conform to a traditional system with only minor modifications? A manual system that must be significantly tailored to the 
student's production capacity is probably not the system of choice. A manual system requires that the student learn and maintain a predetermined set of signs. Modification of a traditional sign system reduces the universality of understanding of the student's vocabulary. Individuals who are unfamiliar with the student's modifications cannot understand his/her particular language. Thus, the audience is severely limited. The pairing of printed words with symbols on a communication board, however, enables symbol modification to the maximum extent necessary for the board user without masking meaning. When the need for extensive modification presents itself, a board system is preferable.

8. Do the parents have preferences? Parental agreement and involvement in decisions concerning the nonvocal system to be used are important. Parental preference should be taken into account to ensure that use of the nonvocal system is generalized beyond the classroom into the home.

\section{Decision Step 4: \\ Within the Chosen Category, Which Language System Should be Selected?}

Once the interdisciplinary team has selected which of the three major categories of nonvocal communication is most appropriate for the student, a determination of the language system within the chosen category must be made.

\section{Category of Manual Communication}

If manual communication has been selected as the most appropriate category for the student, the team may then select from several manual language systems: idiosyncratic gesturing (Hamre-Nietupski, Stoll, Holtz, Fullerton, Ryan-Flottum, \& Brown, 1977), American Indian Sign (Skelley, 1977; Skelley, Schinsky, Smith, Donaldson, \& Griffin, 1975; Tomkins, 1969), American Sign Language (Fant, 1972), or Signing Exact English (Gustason, Pfetzing, \& Zawolkow, 1972). To assist in making a selection among these systems, two questions may be asked:

1. Is one of the language systems currently being used by an essential community? Is one of these systems already in general use by the people with whom the student will come in contact most frequently? Consideration should be given to the system currently being used by the parents and by teachers and peers in the school setting. Additionally, consideration should be given to the system that may be in use in future vocational and community settings. The functional advan- tage of an immediate audience supports use of a locally popular system.

2. What is the student's functional level? The degree of sign iconicity and grammatic complexity of the language system should be matched to the student's functional level. Iconicity of a sign refers to how much the sign resembles the item/action it represents. The lower the functioning level of the student, the greater is the iconicity that may be required for him/ her to understand and reproduce a sign. If idiosyncratic gesturing is selected, these gestures derived from current student usage will probably have the most meaning for the student (Nietupski \& Hamre-Nietupski, 1979).

Of the standard sign systems, American Indian Sign (Amerind) operates at a very reduced symbolic level and is therefore highly iconic (Skelley, 1977). Observers can interpret Amerind with over $80 \%$ comprehension without previous instruction, suggesting a high degree of iconicity (Skelley, Schinsky, Smith, \& Fust, 1974). American Sign Language (ASL), used by a large number of deaf persons in the United Staes, retains a higher degree of iconicity than Signing Exact English (SEE) (Babbini, 1974). ASL signs represent concepts in contrast to representation of isolated or individual words as is the case in SEE.

The second consideration is the degree of grammatic complexity within the signing system. Amerind "has no required grammatical or structural rules" (Skelley, 1977). SEE is complex in that it resembles spoken English and includes inflections of tense and linear syntax paralleling verbal language structure. Because of its close parallel with spoken and written English, SEE may be the system of choice for potential readers. ASL constitutes a separate language from English (Stokoe, 1970). ASL is a system that uses signs to represent whole concepts, and it has its own grammatic rules and structures.

\section{Category of Communication Boards}

Within this category of nonvocal communication are a variety of specific language systems from which to select. Arranged in a hierarchy from the most concrete to the most abstract, these systems include the use of objects, photographs, magazine pictures, commercially made picture drawings (Maharaj, 1980), line drawings, Blissymbolics (Bliss, 1965), traditional orthography (words), and letters. Selecting from among these systems should consider the following questions.

1. What degree of representation (iconicity) does the student need? Moving up the hierarchy, the symbols become more abstract and, therefore, more representational. A student who has not mastered the concept of 
object permanence may have difficulty with symbols that do not "mimic" what they represent. For cognitively delayed students, highly concrete symbols (e.g., objects, photographs, magazine pictures, pictograms) may be more appropriate.

2. What is the need for extended vocabulary and for a vocabulary that can make discrete differences of meaning? A student with receptive language and cognitive potential to attain extensive vocabulary and complex, multi-word communication is a candidate for Blissymbols, traditional orthography, letters, or a combination of these. This type of system allows students to create a large number of concepts as language needs arise. The structure of these systems enables the combination of symbols to express new concepts, thereby freeing cognitively able students from the constraints of more fixed, concrete systems.

3. How much time is required to instruct the student in use of the system? Two studies have investigated the amount of teacher time required for instruction and the number of trials to mastery of symbol systems. When pictograms were compared with Blissymbols, the results suggested that the iconic pictures are more readily acquired, maintained, and generalized (Hurlbut, Iwata, $\&$ Green, 1982). When comparing pictograms, Blissymbols, and traditional orthography, pictograms were found to be the most efficient and effective for instruction, followed by Blissymbols and then traditional orthography (Briggs, 1983).

Although a team may select one symbol system, a student might be able to utilize more than one system as the board develops. A student might begin with photographs, but as he/she becomes a more fluent communicator and as cognitive skills develop, the student may gradually transfer to more abstract, flexible symbols.

\section{Category of Communication Codes}

Use of a communication code should be selected when no other alternative is available. Communication codes are usually employed with only the most physically disabled students, or with individuals in a rehabilitative setting who need a temporary means to express their needs until recuperation. Codes should be considered for use only if physical impairments preclude all but the most rudimentary motor movements.

Codes are transmitted as response modes in the form of eye blinking or finger and foot tapping, for example. With mentally handicapped students the language content may be as limited as allowing for a yes/no response, or as complex as using the Morse code with higher functioning students. Because codes require the listener to be the initiator of any communication exchange, and knowledgeable in the deciphering technique, the use of codes is extremely limited and, therefore, the most restrictive means of nonvocal communication.

The determination as to what type of code to train is based on the topography of response the student is capable of making. Technological advances have made communication codes unnecessary for most students. Scanning and encoding systems linked to micro-switches have expanded what was thought at one time to be limits prescribed by physical disability. For example, a puff of breath can now activate an elaborate communication system. For a more complete discussion of codes and technological alternatives, refer to Silverman (1980) and Vanderheiden and Grilley (1975).

\section{Decision Step 5: \\ What Will Be the Means of Access?}

When the decision has been made to utilize a particular communication symbol/board system, the means by which the student will be able to access the language elements must be determined. The three basic techniques of access are: direct selection, scanning, and encoding (Vanderheiden \& Grilley, 1975).

1. Direct selection occurs under the complete control of the communicator. Pointing to a specific symbol site on the communication array, the individual initiates and completes symbol selection independently. Pointing may be done by using a body part (e.g., finger), prosthetic device (e.g., head wand), or technical aid (e.g., light beam). The appropriateness of a direct selection system is judged by the student's accuracy and time efficiency allowed by the pointing method.

2. Scanning relies on the assistance of someone else or something else to move a pointing signal across the communication board. As the signal device moves across the array of symbols, the communicator issues the command to indicate when the signal should stop. The position at which the pointing signal is stopped indicates what the communicator is saying. Scanning may be as simple as having the teacher run a finger across the rows of a communication board until the communicator indicates "stop" or it may involve a technical aid such as a light pulse that moves automatically across the board until the communicator flips a stop switch.

When motoric limitations prevent direct selection, scanning is an option because it requires only minimal motor response. Any consistently recognizable signal can be used to "say when." Although scanning does accommodate severe physical involvement, it also requires some cognitive skill beyond direct selection and is a slower procedure. 
3. Encoding uses a limited number of communicator initiated signals that are combined in order to locate the coordinates of a specific site on the communication board. Thus, the communicator indicates the code for the intended word, not the actual word itself. A simple example of encoding is a board with numbered rows and color-coded columns. The communicator first indicates the number of the row of interest and then the color of the column containing the intended symbol. The intersection of number and color gives the location of the symbol of interest. Encoding is useful for individuals with limited range of motion who can use a large expressive. vocabulary. The advantages of expanded vocabulary offered by encoding are balanced by the cognitive demands on the communicator to understand and use the procedure.

Selection of a symbol accessing technique is based on the motor function, cognitive capability, and vocabulary needs of the student. Any method - direct selection, scanning, or encoding - can be facilitated through use of technological aids (Vanderheiden, 1978). Before selecting a commercially produced, automated system, one must determine that the student can interact with its basic format. Therefore, experimentation and practice with teacher-made access systems are beneficial. Simple arrays and accessing techniques can always be made more complex as the student indicates the need and aptitude for a more sophisticated communication system.

Vanderheiden and Grilley's (1975) book provides a detailed survey of the realm of accessing possibilities available to teachers. As long as the student evidences a consistent operant response, some sort of access technique apparently can be devised. Motor imitation training may be used to teach students who initially lack consistent response.

\section{Decision Step 6:}

\section{Selection of Initial Vocabulary}

When choosing either a manual system or a communication board system, the following criteria will assist in selecting an initial pool of vocabulary words.

1. Words should reflect the student's functional needs in various settings. Functional words may be determined by taking an inventory of essential daily activities the student encounters most frequently, as well as determining which vocabulary items the student finds reinforcing. Language elements necessary for an instructional exchange (e.g., give me, I don't know) also should be included (Grinnell, Detamore, \& Lippke, 1976; HamreNietupski, Stoll, Holtz, Fullerton, Ryan-Flottum, \& Brown, 1977; Richardson, 1975).
2. Words that allow the student to express basic human needs are necessary. Vocabulary items enabling communication of pain, hunger, and toileting needs are taught to enable the student to alert others and thereby help to reduce inappropriate behavior. Including "feeling words" (e.g., happy, sad, angry) allows the student the basic human dignity of self-expression.

3. The student should be provided with an expressive mode for his/her current receptive vocabulary.

4. Inclusion of preferred items will allow a motivational element for communication. The teacher should observe whether the student indicates preferences for certain objects such as a favorite toy.

5. One of the criteria that should be taken into account for sign selection should be the actual motor requirements of sign production. Words that are represented easily help the student experience successful initial language efforts. Although use of functional or motivational objects is essential in determining which signs to train, it should not be the only factor in initial sign selection (Stremel-Campbell, Cantrell, \& Halle, 1977).

Research has identified motor dimensions of signs that are significant to initial learning. These dimensions are iconicity, or how much the movement looks like what the sign represents; taction, or whether there is contact with the body in making the sign; and symmetry, or whether symmetrical or asymmetrical movement of the hands is required to produce the sign. To promote faster acquisition, initial signs should be symmetrical, have taction, and be iconic (Kohl, 1981).

6. Words representing general concepts rather than discrete definitions may be desirable. Initially, generic terms may be selected when specific item terms are too difficult to produce either cognitively or motorically (e.g., one sign or symbol to represent all cookies).

7. An initial vocabulary should take advantage of a skill or activity the student already has in his/her behavioral repertoire in terms of conceptualization and production. For example, initial verbs in any system should be based on activity that the student has already mastered, eliminating the need to teach the concept with the new sign or symbol.

When using a manual system, initial signs should take advantage of motor responses already in the student's movement repertoire, thus eliminating the need to teach a new movement pattern with the new sign. For example, the sign for "drink" mimics the actual movement of drinking from a glass. A student who drinks independently has mastered this movement and, therefore, 
should not have difficulty producing the movement signifying "drink."

\section{Decision Step 7: \\ What Is the Order of Initial Instruction?}

After the decisions for steps one through six have been made, instruction can be initiated using the communication system that has been selected.

1. A student's first experience with language should give him/her an immediate degree of environmental control to clearly demonstrate the function of language. Alberto, Briggs, Sharpton, and Goldstein (1981) have suggested that the first phase of instruction should be that of building in an appropriate yes/no response. Yes/no instruction is appropriate in both manual and communication board systems. Starting with a yes/no response allows the student (a) experiences in which the functional utility of appropriate communication is made concrete and may be appropriately reinforced, (b) a language content that may be immediately generalized across settings and agents, (c) means to transfer nonstandard communication of yes (e.g., smiling) or no (e.g., crying) into a more acceptable format, (d) the functional ability to indicate wants and needs appropriately, thus promoting social and emotional control skills, and (e) a method to discriminate between choice items at a basic response level, thereby developing cognitive skills through appropriate decision making. The instruction of yes and no responding may be quickly and efficiently conducted through the basic instructional technology of physical guidance procedures and appropriate reinforcement techniques (Alberto et al., 1981).

2. If the student is using a board system, the second phase of instruction builds in an attention summoning signal. An attention summoning signal is a device that is easily accessible to the student and is used to indicate to others that the student wants to communicate. For example, the nonverbal student may tap a bell to attract the teacher's attention. The method chosen as a signaling source, however, must be used exclusively for that purpose. The signaling device helps the student understand from the beginning of instruction that his/her system may be used to initiate conversation as well as to respond.

3. Instruction of the first vocabulary item is critical. At this initial encounter, when the sign or symbol is first presented, the student must learn to make the connection between representation of the sign or symbol and the reality of its referent. Nouns are introduced first because they have the most concrete referents. We suggest that the first noun introduced be the referent for an item that was used as a reinforcer in yes/no instruction. If during "yes training," the item used to occasion yes from the student was a particular toy, that toy should be represented by the first sign or symbol selected for instruction.

4. If a language board system has been selected, three additional considerations must be taken into account in planning for its use by the student:

a. Size of the symbol. Considering the visual acuity of the student, one must determine the appropriate size of the symbols to be placed on the board. A procedure patterned after the Parson's Visual Acuity Project (Cress, Spellman, DeBriere, Sizemore, Northam, \& Johnson, 1981) might be followed. This involves teaching the student a simple discrimination task using a symbol card for "correct" (a known picture) paired with an "incorrect" distractor. Starting with relatively large cards, the student is asked to point to the correct card. The size of the stimulus cards is systematically reduced as this task continues. The point at which the student is no longer able to make the appropriate response indicates the point at which the card becomes too small. Therefore, the size of symbols should be the size of the last correctly identified "correct" card.

b. Symbol placement and order of instruction. The general organization of the board is based on the Fitzgerald Key (1949). Figure 2 presents suggested sequences for placement of symbols on an initial communication board.

(1) Yes, the first symbol to be taught, is placed in the upper lefthand corner.

(2) No is placed in the upper righthand corner.

(3) Nouns are placed on the righthand side of the board. Five nouns should be chosen from the pool of initial vocabulary developed during Step 6. As previously indicated, the first noun should be the object used as a reinforcer in yes/no instruction. The second and third nouns should be two more concrete objects; and nouns four and five should be two places, such as toilet and home.

(4) Five verbs are selected from the initial vocabulary pool. The first verb selected should be "want" (Keogh \& Reichle, 1982). The inclusion of "want" gives the student a means to differentiate between object identification and object requests (i.e., "apple" identification is differentiated from "I want apple").

The second verb suggested is "go." "Go" may be taught as the motoric opposite of "want." "Want" indicates bringing an object to the speaker; "go" 
Student's Name

1

$$
\begin{aligned}
& \text { YES } \\
& +! !
\end{aligned}
$$

4

Verbs
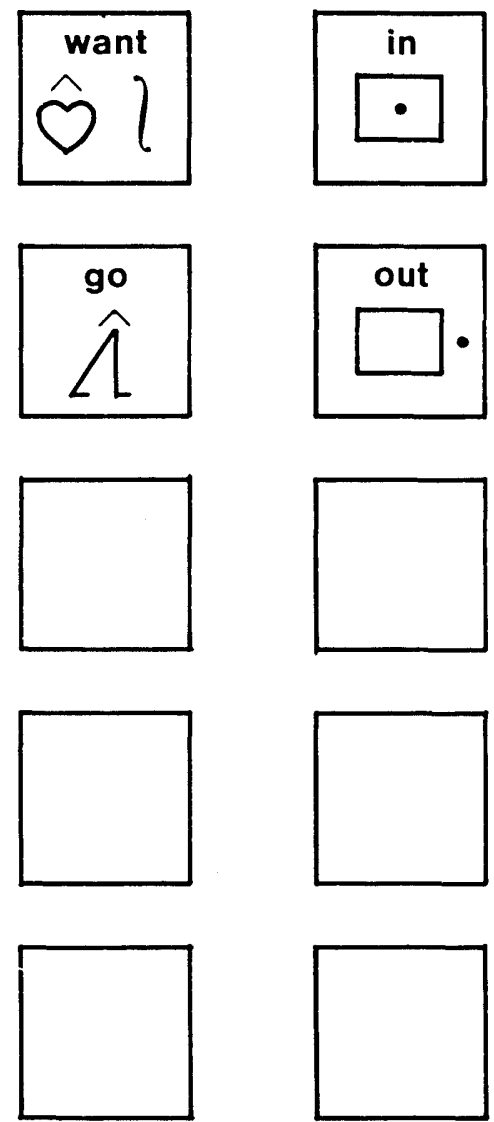

7

Prepositions
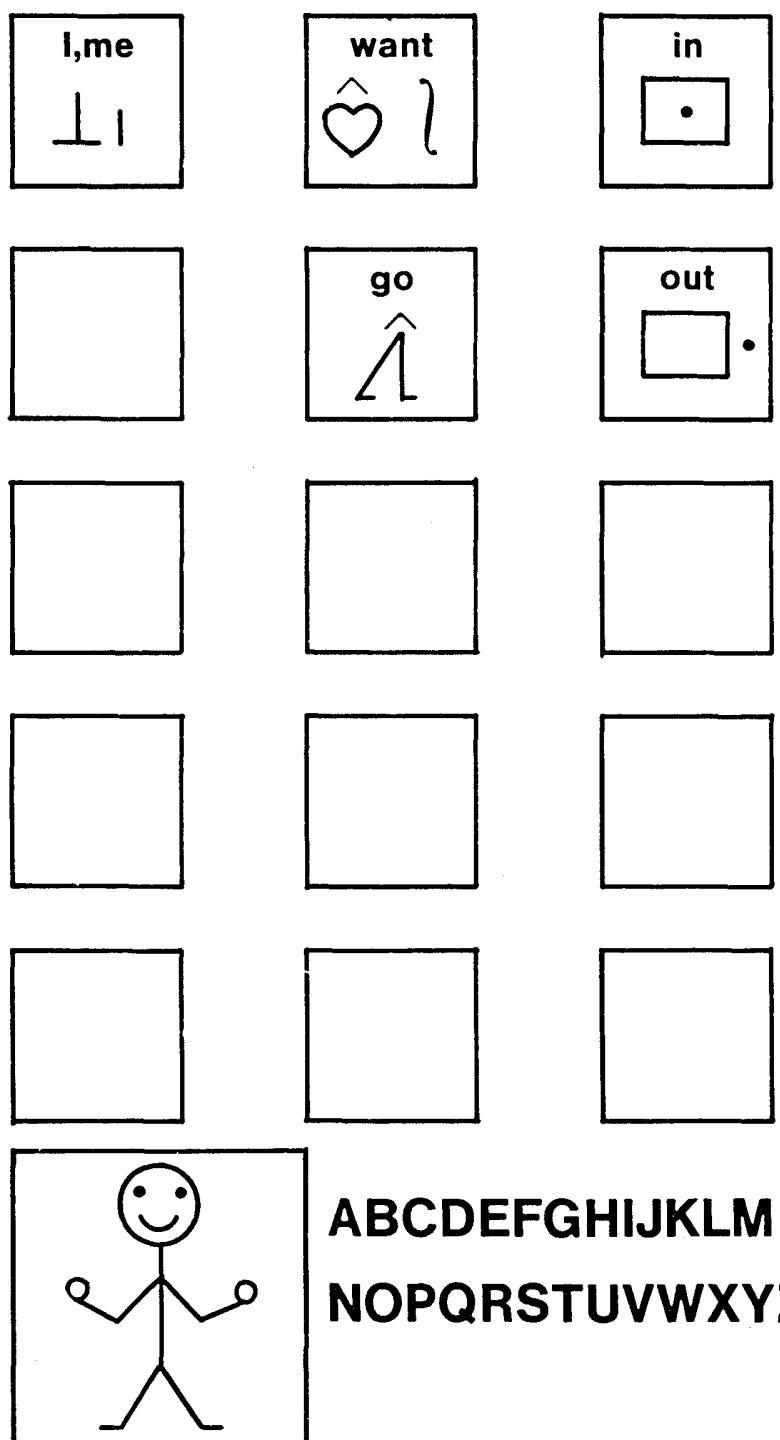

ABCDEFGHIJKLM NOPQRSTUVWXYZ

\section{0}

2

NO

$-! !$
6

Adjectives

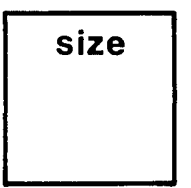

3

Nouns

Reinforcer

used in

Yes/No

Instruction

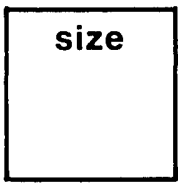

object
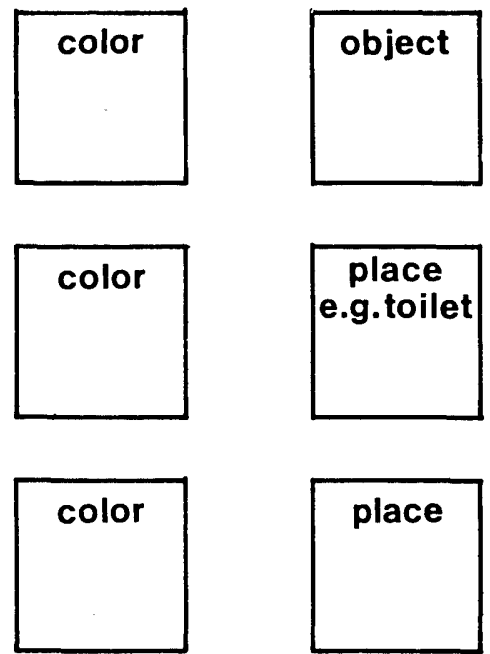
indicates movement toward an object. Instruction may center on discriminating between these two actions, matching the actions with the symbols. Further support of "go" comes from the finding that "go" is the most frequent mover-location action verb produced by children at the initial stages of language acquisition (Bloom, Miller, \& Hood, 1978).

(5) The next item instructed is a list of agents. Agent symbols are placed on the extreme lefthand side of the board. We suggest that the first agent listed be "I, me." The student may then be taught to communicate sentences such as "I want ..." The remaining four agents should be persons most frequently in contact with the student, such as the parent, teacher, speech pathologist, and paraprofessional.

(6) Placement of adjectives follows next. Initial adjectives should refer to size and color, as they are two of the three relevant dimensions to which children first attend when considering new stimuli (Gruen \& Berg, 1973; Lovaas, Schreibman, Koegel, \& Rehm, 1971).

(7) Next is placement of prepositions. The first prepositions suggested for instruction are "in" and "on." These are the first prepositions to emerge in normal language acquisition (Brown, 1973) and are clearly discriminate opposites.

Following this initial symbol instruction, the student has a basic 25 -word vocabulary selected from the initial vocabulary pool. This vocabulary contains all the basic grammatic elements. The symbols are placed so that the student will be able to move from left to right, making a grammatically correct sentence.

No matter which symbol system is used, the printed word should appear directly above the symbol on each symbol card. As vocabulary is increased, columns of symbols may be extended or doubled depending on the size of the board. Color coding word categories (e.g., agents - yellow, verbs - red) will assist the student's rate of scanning the board for a particular symbol.

Figure 2 is a standard starting format in a communication board design. Though this figure represents a typical format, the student's range of motion must be taken into account when planning specific symbol placement. A board should always be arranged to facilitate the student's ease of selection. For example, if a student has a pointing response that is functional solely in the lower right quadrant of the board, symbols should be placed in that quadrant only. If a student is using eye pointing for symbol selection, the space between symbols may be exaggerated for greater clarity.
When adapting the symbol layout, care should be taken not to reinforce any inappropriate primitive reflexes (e.g., asymmetric tonic neck reflex). A student should not be asked to use a primitive reflex to point.

Additional functional symbols may be added to a student's board. One example is to include a representational stick figure in the lower lefthand corner (note Figure 2). By pointing to arm, leg, etc. on the stick figure, the student is able to talk about specific body parts. This symbol, therefore, provides a space-efficient means for identifying body parts quickly (McDonald, 1980). Also, a number line placed across the top of the board and an alphabet across the bottom allows a student information to use in the communication process or can serve the teacher as instruction continues. Cognitively capable students will use the number line in academic as well as informal responses. Using the letters to spell new words vastly increases the number of concepts a higher functioning student can generate.

c. Portability. A major consideration in the development of a communication board is to make sure the student can handle it without difficulty. Limited portability reduces the student's opportunities for functional use of the board. Ready access to symbols is necessary to ensure spontaneous, continuous, and generalized use of communication.

To devise the most functional design, the team should consider the student's manipulation and mobility skills. Popular arrangements include fixing the board to the lap tray of a wheelchair, adding a shoulder strap to the board so it can be turned easily, or enclosing the board within a file folder. For students who are unable to position the board themselves, the attention summoning signal may be used to express, "I want to talk; please place my board so that I may use it." Ensuring that students can use their boards whenever they wish is necessary not only to increase their desire to use the board, but also to encourage others to interact with their special language programs.

As the student comes to use an increasing number of symbols, specific mini-boards may be developed to increase portability. For example, the student may carry a card in his/her wallet displaying only the symbols required in using public transportation. Mini-boards may also be developed to accommodate unique vocabulary requirements for a particular setting. For example, the student may have a board that displays symbols needed in the vocational setting or for grocery shopping.

\section{AUTOMATED COMMUNICATION}

Technology supplies an extensive variety of access and output modes that may be combined to create a fully 
automated communication system. Matching the appropriate system to the student is essential to ensure that (1) the system is functional and (2) the cost is justified.

Before considering an automated system, the student's positioning needs must be determined and accommodated. After functional positioning has been developed, the teacher/clinician should experiment with the accessing techniques described in Step 5. Prior to investigation of commercial products, an accessing technique based on the student's cognitive ability and response mode should be identified and trained so that the student is proficient with some form of teacher-made communication system. This assures that functional communication is not delayed while awaiting a specific technology, and it provides a basis for choice among the broad spectrum of commercial products.

\section{Factors in Evaluating Commercial Systems}

When evaluating commercial systems, several factors must be taken into account. The system should be adaptable to accommodate the customized positioning, accessing, and symbol array required by the student. The system should be flexible to keep pace with expansion of the student's vocabulary. And it should be applicable to a variety of uses (e.g., peer interaction, telephone conversation, written message recording).

Also, portability is essential to ensure that the system has generalized utility. The user must be able to transport it to a variety of settings. Systems that may be mounted on a wheelchair have an obvious advantage to nonambulatory students. In addition, a system that has a built-in call signal increases its interactive potential across settings.

Durability is mandatory. A system should be resistant to damage from moisture and impact. This feature is required by users who experience uncontrolled drooling and involuntary movement. Several systems offer additional protective coverings to enhance durability.

Related to durability is the requirement of appropriate service and warranty. If a system is damaged, the distributor/manufacturer must have reasonable repair and replacement guarantees to establish that the system will be useful over time.

Expense is a significant factor. Careful analysis is required to determine whether the specific features made available through technology are necessary. In many cases, a totally functional communication system can be constructed without having to resort to commercial communication packages and, thus, without the expense of current automated systems.
Most importantly, the student must recognize the advantage of automation. A system that the student views as neither desirable nor functional will not be used optimally. Therefore, the student's input and attitude are controlling factors throughout the decision process.

\section{Examples of Commercially Produced Automated Communication Systems}

Names and addresses of manufacturers of the systems discussed below are provided at the end of this article. This sampling of products indicates the variety of sources available.

Both Voc Aide (Texas Instruments) and Handivoice (Phonic Mirror) provide a fixed array of vocabulary items. Mode of access is by direct selection, and output is auditory. Because the vocabulary items are predetermined, the expressive repertoire may not match the user's level or needs. The feature of auditory output, however, enables users to interact with any listeners who are not hearing impaired. Therefore, these devices facilitate peer interaction since output is heard and not read, removing the requirement of normal vision and reading ability.

Versa Scan (Prentke Romich Company) and Zygo Model 16 (Zygo Ind ustries) provide a format for access by scanning. The user determines the vocabulary array. Both systems utilize a light pattern to scan. Versa Scan employs a circular scan; Zygo Model 16 utilizes row/ column scanning. Vocabulary items are superimposed over each device and may appear in any form (pictures, symbols, words, letters). The receiver identifies the output as that item which corresponds to the light cue. Thus, these systems are functional only for communication with individuals who have adequate vision and cognitive skills to interpret the illuminated symbol. At the same time, however, the scanning and flexible vocabulary features enable Versa Scan and Zygo Model 16 to be utilized as an expressive system for students with significantly impaired motor and cognitive ability.

The Canon Communicator (Canon USA) and Sharp Memorwriter (Sharp Electronics) utilize direct selection of letters on a keyboard to produce printed communication, which is displayed on a tape printout. The Sharp Memorwriter also includes a calculator dimension. The requirement of generating words and sentence structure limits these two systems to individuals without significant cognitive impairment. The permanent printout of communication is certainly a useful feature for those who are able to use these systems.

The Autocom (Prentke Romich) and Express 3 (Prentke Romich) offer a selection of access modes 
(direct or scanning), a flexible vocabulary (programmed by the user), and a variety of output modes (auditory, printed tape, or liquid crystal display). An additional feature is that these systems may be linked to a computer (Apple) to program input or receive output. Not surprisingly, the significantly increased versatility and sophistication of these systems is accompanied by significantly increased expense.

\section{When to Invest}

In some cases, the expense of a commercial communication system is balanced by its benefits to the user. But first, the student should have mastered some teachermade system demonstrating that positioning and potential accessing technique have been addressed. The fa mily must be able and willing to maintain and reprogram an automated system when the student leaves the school environment. The communication skill of the student should have reached a level of maturity to ensure that the automated system will not become obsolete soon after its adoption. The student's vocabulary needs should have exceeded the limits of what is available using teacher-made systems.

Finally, at some point the student's need for interaction with others or with information processing equipment may be met only by an automated system. When the student's needs exceed what the teacher or clinician can accommodate, a commercial automated system may be considered.

\section{REFERENCES}

Achilles, R. Communicative anomalies of individuals with cerebral palsy. Cerebral Palsy Review, 1955, 16, 15-24.

Alberto, P., Briggs, T., Sharpton, W., \& Goldstein, D. Teaching a nonverbal yes/no response to severely handicapped students. Journal of Childhood Communication Disorders, 1981, 5, 90-103.

Babbini, B. Manual communication: Finger-spelling and the language of signs. Urbana: University of Illinois Press, 1974.

Bates, E. Language and context: The acquisition of pragmatics. New York: Academic Press, 1976.

Bates, E., Camaioni, L., \& Volterra, V. The acquisition of performatives prior to speech. Merrill-Palmer Quarterly, 1975, 21, 205-266.

Bliss, C. K. Semantography. Sydney, Australia: Semantography Publishing Co., 1965.

Bloom, L., Miller, P., \& Hood, L. Variations and reduction as aspects of competence in language development. In L. Bloom (Ed.), Readings in language development. New York: John Wiley, 1978.
Briggs, T. An investigation of the efficiency and effectiveness of three nonvocal communication systems with severely handicapped students. Unpublished doctoral dissertation, Georgia State University, 1983.

Brown, R. A first language: The early stages. Cambridge, MA: Harvard University Press, 1973.

Chapman, R., \& Miller, J. Analyzing language and communication in the child. In R. L. Schiefelbusch (Ed.), Nonspoken language and communication: Acquisition and intervention. Baltimore: University Park Press, 1980.

Cress, P., Spellman, C., DeBriere, T., Sizemore, A., Northam, J., \& Johnson, J. Visual screening for persons with severe handicaps. Journal of the Association for the Severely Handicapped, 1981, 6, 41-49.

Fant, L. Ameslan: An introduction to American Sign Language. Silver Spring, MD: National Association of the Deaf, 1972.

Fitzgerald, E. Straight language for the deaf. Washington, DC: Alexander Graham Bell Association for the Deaf, 1949.

Flavell, J. Cognitive development. Englewood Cliffs, NJ: PrenticeHall, 1977.

Grinnell, M., Detamore, K., \& Lippke, B. Sign it successful Manual English encourages expressive communication. Teaching Exceptional Children, 1976, 8, 123-125.

Gruen, G., \& Berg, B. Visual discrimination learning in familial retarded and non-retarded children. American Journal of Mental Deficiency, 1973, 78, 63-69.

Gustason, G., Pfetzing, D., \& Zawolkow, E. Signing Exact English. Rossmoor, CA: Modern Signs Press, 1972.

Hamre-Nietupski, S., Stoll, A., Holtz, K., Fullerton, P., RyanFlottum, M., \& Brown, L. Curricular strategies for teaching selected nonverbal communication skills to severely handicapped students. In L. Brown, J. Nietupski, S. Lyon, S. Hamre-Nietupski, T. Crowner, \& L. Gruenewald (Eds.), Curricular strategies for teaching nonverbal communication, functional object use, problem solving and mealtime skills to severely handicapped students (Vol. 7, Part 1). Madison WI: University of Wisconsin-Madison and Madison Metropolitan School District, 1977.

Harris-Vanderheiden, D., Brown, W., MacKenzie, P., Reiner, S., \& Scheibel, C. Symbol communication for the mentally handicapped. Mental Retardation, 1975, 13, 34-37.

Hurlbut, B., Iwata, B., \& Green, J. Nonvocal language acquisition in adolescents with severe physical disabilities: Blissymbol versus iconic stimulus formats. Journal of Applied Behavior Analysis, $1982,15,241-258$.

Ingram, D. The transition from early symbols to syntax. In R. L. Schiefelbusch \& D. D. Bricker (Eds.), Early language: Acquisition and Intervention. Baltimore: University Park Press, 1981.

Irwin, $O$. An integrated articulation test for use with children with cerebral palsy. Cerebral Palsy Review, 1961, 22, 3-20.

Kahn, J. Relationship of Piaget's sensorimotor period to language acquisition of profoundly retarded children. American Journal of Mental Deficiency, 1975, 79, 640-643.

Keogh, W., \& Reichle, J. Teaching "want." Paper presented at the national conference of The Association for the Severely Handicapped, Denver, November 1982.

Kohl, F. Effects of motoric requirements on the acquisition of manual sign responses by severely handicapped students. American Journal of Mental Deficiency, 1981, 5, 396-403.

Kotkin, R., \& Simpson, S. A sign in the right direction: Language development for the non-verbal child. AAESPH Review, 1976, 1, 75-81.

Lovaas, O., Schreibman, L., Koegel, R., \& Rehm, R. Selective responding by autistic children to multiple sensory input. Journal of Abnormal Psychology, 1971, 77, 211-222.

McDonald, E. Teaching and using Blissymbolics. Toronto: Blissymbolics Communication Institute, 1980.

Maharaj, S. Ideogram communication. Saskatchewan, Canada: George Reed Foundation, 1980. 
Mecham, M., Berko, M., Berko, F., \& Palmer, M. Communication training in childhood brain damage. Springfield, IL: Charles C Thomas Co., 1966.

Mysak, E. Dysarthria and oropharyngeal reflexology: A review. Journal of Speech \& Hearing Disorders, 1963, 28, 252-260.

Nicolosi, L., Harryman, E., \& Kresheck, J. Terminology of communication disorders. Baltimore: Williams \& Wilkins Co., 1978.

Nietupski, J., \& Hamre-Nietupski, S. Teaching auxiliary communication skills to severely handicapped students. AAESPH Review, $1979,4,107-124$.

Piaget, J. The origins of intelligence in children. New York: Norton, 1952.

Reich, R. Gestural facilitation of expressive language in moderately and severely retarded preschoolers. Mental Retardation, 1978, 16, 113-116.

Reichle, J., \& Yoder, D. Communication behavior for the severely and profoundly mentally retarded: Assessment and early stimulation strategies. In R. York \& E. Edgar (Eds.), Teaching the severely handicapped (Vol. 4). Columbus, OH: Special Press, 1979.

Richardson, T. Sign language for the severely mentally retarded and profoundly mentally retarded. Mental Retardation, 1975, 13, 17.

Robinson, C., \& Robinson, J. Sensorimotor functions and cognitive development. In M. Snell (Ed.), Systematic instruction of the moderately and severely handicapped. Columbus, $\mathrm{OH}$ : Charles $\mathrm{E}$. Merrill, 1978.

Schaeffer, B. Teaching signed speech to non-verbal children: Theory and method. Sign Language Studies, 1980, 26, 20-63.

Schaeffer, B., Kollinzas, G., Musil, A., \& McDowell, P. Spontaneous verbal language for autistic children through signed speech. Sign Language Studies, 1977, 17, 287-328.

Scheuerman, N., Baumgart, D., Spisma, K., \& Brown, L. Toward the development of a curriculum for teaching nonverbal communication skills to severely handicapped students: Teaching basic tracking, scanning and selection skills. In N. Scheuerman, L. Brown, \& T. Crowner (Eds.), Toward an integrated therapy model for teaching motor, tracking, and scanning skills to severely handicapped students (Vol. 6, Part 3). Madison, WI: Madison Metropolitan School District, 1976.

Silverman, F. Communication for the speechless. Englewood Cliffs, NJ: Prentice-Hall, 1980.

Skelley, M. Indian sign (Amerind), distinctive characteristics differentiating it from other sign systems. ASHA, 1977, 19, 746-747.

Skelley, M., Schinsky, L., Smith, R., Donaldson, R., \& Griffin, J. American Indian Sign: A gestural communication system for the speechless. Archives of Physical Medicine, 1975, 56, 156-160.

Skelley, M., Schinsky, L., Smith, R., \& Fust, R. American Indian (Amerind) as a facilitator of verbalization for oral verbal apraxic. Journal of Speech \& Hearing Disorders, 1974, 39, 445-456.

Stokoe, W. Sign language diglossia. Studies in Linguistics, 1970, 21, $27-41$.

Stremel-Campbell, K., Cantrell, D., \& Halle, J. Manual signing as a language system and as a speech initiator for the nonverbal severely handicapped student. In E. Sontag (Ed.), Educational programming for the severely and profoundly handicapped. Reston, VA: Council for Exceptional Children, 1977.

Tomkins, W. Indian Sign Language. New York: Dover, 1969.

Vanderheiden, G. (Ed.). Nonvocal communication resource book. Baltimore: University Park Press, 1978.

Vanderheiden, G. The practical applications of high and low technologies to aid communication in non-vocal severely physically handicapped individuals. Paper presented at the regional conference of the Southeast Regional Coalition for Personnel Preparation to work with the Severely/Profoundly Handicapped, Atlanta, 1981 .

Vanderheiden, G., \& Grilley, K. (Eds.). Non-vocal communication techniques and aids for the severely physically handicapped. Baltimore: University Park Press, 1975.

\section{MANUFACTURERS OF AUTOMATED COMMUNICATION SYSTEMS}

\author{
Canon USA, 1 Canon Plaza, Lake Success, NY 11042
}

Phonic Mirror, Inc., 250 Camino Alto, Mill Valley, CA 94941

Prentke Romich Co., 8769 Township Road 513, Shreve, OH 44676-9421

Sharp Electronics, 10 Sharp Plaża, Paramus, NJ 07652

Texas Instruments, Attn: Calculator Division, P.O. Box 53, Lubbock, TX 79415

Zygo Industries, P.O. Box 1000, Portland, OR 97207

\section{CLASSROOM FORUM}

\author{
Beverly Dexter \\ Lynchburg College
}

I teach in a middle school program for learning disabled students and am currently working toward having several of my students mainstreamed into the academic areas with their peers. These students are capable of keeping up with their classmates, but they will still need special help from their teachers in order to meet the classroom requirements. What are some suggestions I can give to their classroom teachers to help make everyone more successful in this new venture?

One of the primary concerns of your teachers will probably be the capabilities of the students you are recommending for placement in the classroom setting. Since you have stated that these students have the necessary capabilities, you will probably want to indicate to the teachers why you think regular classroom placement is best for these students right now. Your explanations should be highlighted with samples of work completed in your room, along with other relevant observations concerning your students' learning behaviors. This will give you an opportunity to discuss each student individually and to explain to each teacher the learning characteristics of these students. Although the 
strengths should definitely be emphasized, don't forget to point out the weaknesses also. Be sure to do this in a realistic manner so that the regular teachers will not feel that they have been "sold short" on a student's abilities when the student shows signs of frustration or failure.

You might review the learning problems the student has experienced in the past and use these as a basis for comparison with the current level of success. Share with the teacher the techniques you used during your work with the student, but remember that the regular teacher may not be able to duplicate all of these methods within the structure of his or her classroom. Discuss with each teacher any adaptations that seem feasible, pulling from strengths you perceive in the teacher that will benefit your student. Remember, mainstreaming is a two-way street, and positive reinforcement is necessary for success in teaching as well as in learning.

One problem that often concerns teachers in this situation is the student's apparent inability to become organized - to "get his (her) act together." Many learning disabled students just do not have a system for organizing information. Over the years they have learned scattered pieces of information or splinter skills that they have been unable to piece together into a meaningful whole. Thus, their performances have been inconsistent - a skill is here today and gone tomorrow! They have struggled with a lot of "hunt and guess" activities in order to survive academically, yet they have frequently failed to learn or retain what they experienced during learning activities. After a while, their response to new learning situations becomes one of "I can't do it" because of their high rate of failure in similar situations.

These students will need directions for tasks spelled out clearly for them. They should be told the reason for learning a new skill, both the immediate and long-range goals for mastering the skill, and what must be done to master it. Task cards outlining the above may be useful for both the teacher and the student. These may even be used to check progress during the learning process, and the students could then be encouraged to keep track of their own progress individually.

Self-checking is only one way of providing feedback to the student on progress, but it is one that encourages independence and responsibility in the student for his or her own learning. Another way, the most frequently used, is to grade or mark errors on papers, homework assignments, worksheets, and so on. This can be defeating to both the student and the learning process if errors are only marked incorrect, without any explanation or opportunity for feedback to and from the student. One way to improve upon this method is to have the students turn in their work in pencil; then, mark the errors also in pencil. Give the student a chance to erase the incorrect answer and try again for the correct one. Before this system is implemented, however, you should understand that the technique is useful only when the teacher feels confident that the student knows the correct answer or can find it through a meaningful activity. If the student merely guessed in the first place, he or she will likely guess again - and again guess incorrectly!

Variations of this method may be introduced to the students as they become more independent in the learning process. For grading purposes, the number of possible points for a corrected answer may be reduced each time it is corrected. Or the incorrect answer may be indicated but the student is not to erase it; instead, he or she places the correct answer next to the incorrect one originally selected. This may also cue the student as to where he or she made the mistake the first time. The corrected paper should then be graded as soon as possible after the student has made all corrections. The corrected paper should be discussed in terms of where the student made the mistakes, why they were made, and possible activities that will help prevent making the same mistake again.

The latter activities should be carefully developed so they do not emphasize rote learning merely for the sake of later recall that is not meaningful to the student. Overlearning can be a useful tool to the learning disabled student, but it should not be confused with "overkill," in which busywork and the like become monotonous and unnecessary drill. Further, although practice makes perfect, the practice must first be done correctly. Many learning disabled students spend as much time having to unlearn incorrect responses as they do trying to learn the correct responses. Much time can be saved if the student is taught in a manner that ensures learning the skill correctly in the first place.

Finally, one should recognize that "individualized" does not mean individual or one-to-one instruction, despite common belief to the contrary. Rather, it means trying to meet a student's individual learning needs and providing instruction to meet that end. Students do not have to be taught alone in an isolated setting. Many times they can learn just as well (or even better) when placed in a group that is not quite on their own level. After all, are any two students exactly on the same level at the same time with the same general learning needs and interests? The trick is to find a group of students on similar levels, with similar learning needs and interests. This can be done only through conscientious observation and assessment of each student. Thus, what is recommended for the learning disabled student is also recommended for all students. 